\title{
IMPLEMENTASI PROGRAM PARENTING TENTANG STIMULASI MEMBACA, MENULIS, BERHITUNG BAGI ORANG TUA DAN GURU PAUD LIMO DEPOK
}

\author{
Ana Widyastuti \\ Program Pendidikan Bahasa Inggris, Fakultas Bahasa dan Seni Universitas Indraprasta PGRI \\ Jl. Nangka 58 Tanjung Barat, Jakarta Selatan, Indonesia, \\ Email: anawidyastuti35@gmail.com
}

\begin{abstract}
The implementation of community service aims to provide counseling how to the solution and how to stimulate children about reading, writing, and arithmetic for parents and early childhood teachers in the district of Limo Depok. The dilemma of reading, composing or so-called calistung is a classic problem that parents feel in almost every region of Indonesia. The fact that primary schools, especially public schools, are still in need of kindergarten children to primary school must be able to calistung. Worry if her child can not read, write and count after graduating kindergarten, making parents demand that the school guarantee the child can calistung. These parents complain that if they are ignored they will move their child to another school. The dilemma is also felt by the school or teachers, if they will lose students then the school income will decrease. Though the competition is very tight because many schools standing PAUD in the neighborhood. It forces teachers to compete to teach calistung children in various ways. The devotion of this society, the first in the form of counseling how to change the perceptions of parents and teachers that force children to learn calistung at an early age was not justified. Second, parents and teachers together simulation practice play calistung so that later can be practiced at home and at school. It is one of the fun solutions for children that their calistung ability increases, not by forcing children to learn like primary school children. The expected short-term outcomes are parents and teachers have the correct knowledge and perception that it is not allowed to force children to learn calistung. Long-term outcomes are parents and teachers can practice teaching calistung solution in children is by stimulation of creative play.
\end{abstract}

Keywords: parenting program, stimulation, reading, writing and arithmetic, parents and PAUD teachers

\begin{abstract}
Abstrak: Implementasi pengabdian masyarakat ini bertujuan untuk memberikan penyuluhan bagaimana solusi dan cara menstimulasi anak tentang membaca, menulis dan berhitung bagi orang tua dan guru PAUD di kecamatan Limo Depok. Dilema tentang membaca, menulis berhitung atau yang sering disebut dengan calistung merupakan masalah klasik yang dirasakan orang tua hampir di semua daerah di Indonesia. Kenyataan bahwa sekolah dasar terutama sekolah negeri masih banyak yang mengharuskan anak TK masuk SD harussudah dapat calistung. Kekawatiran jika anaknya belum dapat membaca, menulis dan berhitung setelah lulus TK, membuat orang tua menuntut agar pihak sekolah menjamin anak mampu calistung. Keluhan orang tua ini jika tidak diindahkan mereka akan memindahkan anaknya ke sekolah lain. Dilema yang juga dirasakan pihak sekolah atau guru, jika mereka akan kehilangan murid maka pendapatan sekolah akan menurun. Padahal persaingan sangat ketat karena banyak berdiri sekolahsekolah PAUD di lingkungan sekitar. Hal itu memaksa guru untuk berlomba-lomba mengajarkan anak calistung dengan berbagai cara. Pengabdian masyarakat ini, yang pertama berupa penyuluhan bagaimana mengubah persepsi orang tua dan guru bahwa memaksa anak belajar calistung di usia dini itu tidak dibenarkan. Kedua, orang tua dan guru bersama-sama praktik simulasi bermaincalistung agar nanti dapat dipraktikkan di rumah maupun di sekolah. Hal itu merupakan salah satu solusi yang menyenangkan bagi anak sehingga kemampuan calistungnya meningkat, bukan dengan memaksa anak untuk belajar seperti anak sekolah dasar. Luaran jangka pendek yang diharapkan adalah orang tua dan guru memiliki pengetahuan dan persepsi yang benar bahwa tidak diperbolehkan memaksa anak untuk belajar calistung. Luaran jangka panjangnya adalah orang tua dan guru dapat mempraktikkan solusi mengajar calistung pada anak yaitu dengan stimulasi bermain kreatif.
\end{abstract}

KataKunci: program parenting, stimulasi, membaca, menulis dan berhitung, orang tua dan guru PAUD

\section{PENDAHULUAN}

TK Aku Anak Indonesia (AAI) adalah sebuah TK yang baru dua tahun berdiri. Seorang kepala sekolah dan dua orang guru, serta 35 orang murid di tahun ajaran 2017-2018. Beralamat di Jl.
Pinang II, kecamatan Limo Depok, sekolah ini memiliki sarana dan prasarana yang cukup memadai seperti tiga ruang kelas, aula serbaguna, kebun yang cukup luas, dan sebagainya. Program 
parenting di TK ini rutin dilaksanakan setiap dua bulan sekali.

Banyaknya keluhan, kekhawatiran dari para orang tua TK AAI karena anaknya belum dapat membaca, menulis dan berhitung, sampai lulus nanti Hal itu membuat mereka terutama wali murid kelompok B yang berusia 5-6 tahun menuntut pihak sekolah AAI, supaya anaknya cepat pandai membac, menulis dan berhitung. Pihak sekolah telah berusaha menjelaskan, tetapi tetap saja, para orang tua mengeluh dan menuntut terutama guru wali kelas putra putri mereka.

Berdasarkan hal ini, maka pihak yayasan Aku Anak Indonesia mengundang pelaksana abdimas untuk mengisi materi kegiatan parenting tentang Membaca, Menulis dan berhitung (Calistung) ini. Pihak yayasan menganggap perlu diadakan program parenting dengan mengundang para orang tua, dan guru untuk diberikan penyuluhan dan implementasi stimulasi bermain calistung di rumah maupun di sekolah.

Program parenting yang diberikan pada orang tua akan mempengaruh pola asuh orang tua terhadap anak. Pola asuh orang tua adalah pola perilaku yang diterapkan orang tua pada anak dan bersifat relatif konsisten dari waktu ke waktu. Pola asuh adalah suatu cara terbaik yang dapat di tempuh orang tua dalam mendidik anakanaknya sebagai perwujudan dari rasa tanggung jawab kepada anak-anaknya (Mansur, 2015)

Program pendidikan keorangtuaan atau program parenting termasuk ke dalam pendidikan orang dewasa, yang dimana pendidikan orang dewasa menurut (Sudjana, 2010) yaitu diperuntukkan bagi orang dewasa dalam lingkungan masyarakatnya, agar mereka dapat mengembangkan kemampuan, memperkaya pengetahuan, meningkatkan keterampilan dan profesi yang telah dimiliki, memperoleh cara-cara baru, serta mengubah sikap dan perilaku orang dewasa

Parenting adalah upaya pendidikan yang dilaksanakan oleh keluarga dengan memanfaatkan sumber-sumber yang tersedia dalam keluarga dan lingkungan yang berbentuk kegiatan belajar secara mandiri. Parenting sebagai proses interaksi berkelanjutan antara orang tua dan anak-anak mereka yang meliputi aktivitas- aktivitas sebagai berikut: memberi makan (nourishing), memberi petunjuk (guilding), dan melindungi (protecting) anak-anak ketika mereka tumbuh berkembang, dan mengembangkan (mendidik) potensi yang dimiliki anak-anak. Program parenting dirancang oleh pihak sekolah dengan komite. sekolah yang mayoritas orang tua peserta didik di antaranya adalah: kumpulkumpul orang tua dan guru untuk membahas Pendidikan, diadakannyaseminar atau penambahan ilmu pengetahuan dan Pendidikan bagi orang tua. (Helmawati, 2015).

Kegiatan parenting anak usia dini dapat dilaksanakan untuk mengoptimalkan proses Pendidikan anak-anak di antaranya adalah: (1) parents gathering, (2) foundation class, (3) seminar, (4) hari konsultasi, (5) field trip, (6) home activities, (7) cooking on the spot, (8) bazar day, (9) mini zoo, (10) home education video.

Selanjutnya (Helmawati, 2015) mengatakan lagi bahwa tahapan pembentukan program parenting antara lain: (1) melakukan identifikasi kebutuhan orang tua. Setiap orang tua memiliki kebutuhan dan keinginan yang berbedabeda terhadap anak-anaknya yang menjadi peserta didik di Lembaga Pendidikan. Ada orang tua yang ingin anak-anaknya bisa cepat membaca, ada orang tua yang ingin anak-anaknya lebih mandiri, ada orang tua yang ingin anak-anaknya pandai menyanyi dan menari, dan lain-lain. Oleh karena itu, perlu dilakukan identifikasi kebutuhan orang tua yang beragam tersebut sehingga dapat dikembangkan dan dituangkan dalam kurikulum Lembaga Pendidikan, (2) membentuk kepanityaan parenting yang melibatkan komite sekolah sehingga program parenting yang akan dikembangkan betul-betul dapat menjembatani kebutuhan orang tua dan kebutuhan sekolah/lembaga Pendidikan. Panitya program parenting dibentuk dengan susunan yang jelas sebagaimana bagan sebuah organisasi. Dalam bagan tersebut sebagaimana kelengkapan sebuah organisasi antara lain ada ketua, sekretaris, bendahara, kemudian seksi-seksi, seperti: seksi Pendidikan dan pengajaran, seksi perlengkapan dan sarana, seksi dana. Seksi-seksi ini berkembang sesuai masing-masing bagian, (3) membuat job deskripsi masing-masing bagian, (4) menyusun program, (5) menyusun jadwal 
kegiatan, (6) mengidentifikasi potensi dan mitra pendukung, (7) melaksanakan program sesuai dengan agenda, (8) melakukan evaluasi dan kesepakatan bersama.

Dalam layanan pengasuhan pada satuan PAUD dilakukan bekerjasama dengan orangtua melalui program parenting. Program parenting diisi dengankegiatan: (1) KPO (Kelompok Pertemuan Orangtua) seperti penyuluhan, diskusi, simulasi, seminar tentang pertumbuhan dan perkembangan anak, pengenalan makanan lokal yang sehat, pembiasaan perilaku Hidup Bersih dan Sehat (PHBS), Penanggulangan kecacingan, Penggunaan garam beryodium, pencegahan penyakit menular, dan lain-lain, (2) konsultasi antara guru dan orangtua berkaitan dengan pertumbuhan dan perkembangan anak, (3) keterlibatan orang tua di dalam kelas misalnya membantu menata lingkungan main, membuat media pembelajaran, menjadi model profesi sesuai dengan tema pembelajaran, (4) keterlibatan orang tua dalam menyediakan program makan Bersama secara bergilir sesuai rekomendasi ahli gizi tentang penyediaan menu makanan dengan pemenuhan gizi seimbang, (5) keterlibatan orangtua di luar kelas misalnya menjadi panitya kegiatan lapangan, dan menyediakan PMT, (6) kegiatan Bersama keluarga. Kesepakatan antara pihak satuan dengan orangtua untuk dapat terlibat dalam program parenting dapat dilakukan pada saat awal masuk satuam PAUD yang dikuatkan dengan menandatangani surat pernyataan kesanggupan melaksanakan pengasuhan bersama. Satuan PAUD memfasilitasi komunikasi dengan orangtua melalui buku Penghubung dan atau laporan. Buku penghubung merupakan alat komunikasi antara guru dan orangtua tentang pertumbuhan dan perkembangan anak serta informasi lain berhubungan dnegan kegiatan anak di rumah dan di satuan, yang disampaikan setiap saat oleh guru maupun orangtua jika ada peristiwa atau informasi. Buku laporan perkembangan anak merupakan hasil catatan perkembangan anak setelah mengikuti kegiatan di satuan PAUD dalam kurun waktu tertentu, yang dapat disampaikan setiap triwulan atau semester. (NSPK, Norma, Standar, rosedur, dan Kriteria, Petunjuk Tehnie Penyelenggaraan PAUD Holistik Integratif di Satuan PAUD, 2015)
Selanjutnya dipertegas lagi bahwa program kerja dan standar operasional prosedur penyelenggaraan PAUD Holistitik Integratif (HI) di satuan PAUD yaitu penyelenggaraan PAUD HI disesuaikan pada rencana program yang telahdisusun oleh masing-masing satuan PUD sesuai dengan kondisinya. Untuk memudahkan penerpan PAUD HI di satuan PAUD, maka perlu disusun program kerja sebagai berikut: (1) memilah mana kegiatan anak dan kegiatan untuk orang tua (parenting), (2) memilah kegiatan anak yang harus dilakukan secara rutin setiap hari dan kegiatan yang dilakukan rutin setiap bulan, (3) memilah mana kegiatan untuk anak yang dapat dilakukan sendiri olrh guru atau harus dilakukan oleh instansi Pembina datau pihak lain.

Pendidikan Anak Usia Dini (PAUD) merupakan Pendidikan yang paling fundamental karena perkembangan anak di masa selanjutnya akan sangat ditentukan oleh berbagai stimulasi bermakna yang diberikan sejak usia dini. Awal kehidupan anak merupakan masa yang paling tepat dalam memberikan dorongan atau upaya pengembangan agar anak dapat berkembang secara optimal. Stimulasi adalah pemberian rangsangan Pendidikan yang diberikan untuk mencapai kompetensi sikap, pengetahuan, dan keterampilan bagi anak usia dari lahir sampai 6 tahun agar dapat tumbuh dan berkembang optimal. (Kebudayaan, 2015)

Menurut Marhnis Yamin (2007:106), (1) membaca adalah suatu cara untuk mendapatkan informasi yang disampaikan secara verbal dan merupakan hasil ramuan pendapat, gagasan, teoriteori, dan menjadi pengetahuan siswa, kemudian pengetahuan tersebut dapat diserap dalam berpikir, menganalisis, bertindak dan dalam pengambilan keputusan membaca membutuhkan ketrampilan, kebiasaan dan konsentrasi, penguasaan kata dan kecepatan membaca, (2) Tulis, menulis, artinya: (a) Membuat huruf (angka) dengan pena (pensil, kapur,dsb), (b) Melahirkan pikiran atau perasaan (seperti mengarang, membuat surat) dengan tulisan, (c) Membatik (kain), (3) Hitung, menghitung, artinya: Membilangkan (menjumlahkan, mengurangi, membagi dan memperbanyak). (Yamin, 2009). 
Sedangkan menurut (Santoso, 2004) mengatakan bahwa pelajaran membaca, menulis dan berhitung sangat menentukan keberhasilan anak untuk belajar pada jenjang pendidikan selanjutnyaketiga mata pelajaran ini sering disebut 3R yaitu sengkatan dari Read, Write dan Arithmatic. Ketiganya harus diefektifkan pelaksanaannya ketika di sekolah dasar. Sebab pelajaran itu merupakan dasar bagi seseorang untuk mengenyam pendidikan di kemudian hari.

Sedangkan menurut (Carey Lou Dick Walter and Carey, 2009) "Tahap pertama dalam belajar membaca disebut "kesiapan membaca dari sejak lahir sampai sekitar usia 6-7 tahun, kesiapan membaca meliputi berbagai kesiapan belajar diantaranya kesiapan fisik meliputi penglihatan dan pendengaran yang baik, kesiapan intelektual meliputi persepsi visual anak bias menyerap dan mengingat kata-kata dan huruf, kesiapan bahasa meliputi kemampuan berbicara dengan jelas, kesiapan kepribadian meliputi kemampuan bekerja sama dengan anak lain. Yang paling penting diperhatikan usaha percepatan biasanya justru merusak mental, anak belum siap membaca menjadi frustasi jika dipaksa untuk belajar dan perasaan ini mungkinakan terbawa ke jenjang pendidikan selanjutnya"

Ketua Divisi Tumbuh Kembang Anak dan Remaja Departemen Ilmu Kesehatan Anak RSUD Dr. Soetomo Ahmad Suryawan mengatakan calistung tidak boleh dijadikan program evaluasi prestasi pada anak usia dini. Calistung hanya boleh diajarkan kepada anak usia dini dalam bentuk pengenalan. Pengenalan terhadap calistung juga tidak dapat disamakan dengan pengajaran calistung terhadap anak yang memang sudah siap untuk belajar kepada anak usia dini, Calistung bisa diperkenalkan melalui program bermain. Calistung harusnya dikenalkan saja, tidak boleh menjadi program evaluasi prestasi (untuk anak usia dini),". Pengajaran calistung pada anak usia dini memang dipengaruhi oleh tuntutan yang cukup besar. Pasalnya, beberapa SD menerapkan syarat masuk dengan tes calistung. Sistem ini yang harus segera dibenahi oleh pemerintah, baik dari tingkat pusat hingga daerah. Nantinya akan ada satu dampak negatif ketika anak usia dini dipaksa untuk menguasai calistung. Pemaksaan ini, terang Suryawan, akan membuat otak anak tidak bekerja secara runut atau by order. Contoh, ketika seorang anak usia dini diajarkan $9+5=14$, ada dua kemungkinan yang akan terjadi. Salah satunya, anak mungkin sudah siap dan memang mengerti bagaimana proses menambahkan angka 9 dan 5. Akan tetapi, bisa jadi anak tersebut hanya mengetahui jawaban karena menghafal. Sehingga ketika diberikan soal yang berbeda, anak tersebut tidak bisa mengetahui jawabannya. Hal ini yang menunjukkan bahwa otak anak tidak bekerja by order. Karena itu, baca, tulis, hitung, boleh dikenalkan tapi tidak boleh dipakai sebagai syarat untuk evaluasi prestasi di usia itu (Republika, 2017)

Dari paparan-paparan di atas dapat disimpulkan bahwa program parenting merupakan program penting sebagai salah satu sarana atau jembatan komunikasi antara pihak sekolah dan pihak orang tua di rumah, adanya keslarasan cara mendidik, khususnya tentang problema membaca, menulis dan berhitung. Menurut para ahli jelas kiranya bahwa memaksakan belajar anak calistung pada anak usia dini adalah tidak benar. Hal ini dikarenakan ada dampak negatif, yang pastinya orang tua tidak akan menginginkan akan hal itu. Program parenting ini merupakan solusi yang tepat untuk mewujudkan PAUD Holistik Integratif (HI).

\section{METODE PELAKSANAAN}

Dalam kegiatan pengabdian masyarakat ini, pelaksana bertindak sebagai narasumber dan stimulator. Metode yang digunakan adalah ceramah, diskusi, tanya jawab, serta praktik simulasi langsung. Adapun tahapan pelaksanaan pengabdian masyarakat ini adalah sebagai berikut:

Hari pertama, menindaklanjuti dari undangan dari pihak yayasan Aku Anak Indonesia, kecamatan Limo Depok, pelaksana datang ke sekolah untuk membicarakan tentang perencanaan kegiatan parenting. Kesepakatan menentukan tema, tujuan, waktu dan tempat.

Hari kedua, dengan peserta dari orang tua murid dan guru TK Aku Anak Indonesia yang berjumlah 39 orang, pelaksana abdimas mempresentasikan materi mengenai "Membaca, Menulis, Berhitung (Calistung) untuk anak usia 
dini/ TK jika dipaksa belajar Dampak jangka pendek yaitu anak akan mengalami mental heltic, sedangkan jangka panjangnya, kelak jika dewasa dia tidak akan suka membaca, menulis bahkan berhitung atau tidak gemar membaca karena Dampaknya Sesi pertama tentang materi apa itu calistung untuk anak usia dini, sesi kedua tentang polemik dan kekawatiran yang terjadi di masyarakat khususnya orang tua yang anaknya bersekolah di TK Aku Anak Indonesia yang menginginkan anaknya harus pandai calistung kalau lulus TK nanti. Sesi ketiga, tentang dilema guru. Dilema antara harus memenuhi tuntutan orang tua yang mengharapkan anaknya pandai calistung dan larangan pemerintah tentang pengajaran calistung anak usia dini/TK.

Berikutnya ishoma, setelah itu dilanjutkan dengan sesi terakhir yakni diskusi dan tanya jawab tentang keluhan orang tua serta solusi tindakan yang tepat. Solusinya yaitu para orang tua dan guru tetap dapat mengajarkan anak membaca, menulis, berhitung tapi tidak memaksa yaitu dengan mengajak anak bermain. Dengan bermain, anak akan merasa senang, dan anak pun akan menjadi senang membaca.

Hari ketiga, pertemuan dengan peserta, dengan kegiatan praktik stimulasi bermain kreatif dengan media barang bekas, seerti dadu huruf, dadu angka, domino pengenalan kata, menulis dengan pasir dan lain sebagainya. Sebelumnya Semua peserta program parenting yaitu orang tua dan guru TK Aku Anak Indonesia diberi pembekalan bagaimana harus selektif memilihkan permainan yang sesuai dengan usia dan tujuan bermain itu sendiri. Terakhir, peserta mempraktikkan stimulasi bermain kreatif yang bertujuan para mereka dapat memparaktikan di sekolah dan di rumah, sehingga kemampuan membaca, menulis berhitung (calistung) anak menjadi optimal.

\section{HASILDAN PEMBAHASAN}

Hasil dari pelaksanaan abdimas adalah sebagai berikut:

Orang tua murid sangat antusias mengikuti kegiatan penyuluhan ini. Semua peserta hadir. Hampir $70 \%$ aktif bertanya ketika ada sesi pertanyaan. Pertanyaan mereka kebanyakan berisi tentang bagaimana mengajarkan anak di rumah tentang membaca, menulis dan berhitung yang mudah dan menyenangkan bagi anak dan beberapa orang tua murid yang berbagi pengalaman mengenai tes waktu anak tertuanya masuk Sekolah Dasar (SD) yang tesnya sangat sulit serta anaknya tidak diterima di SD tersebut.

Guru-guru di TK Aku Anak Indonesia juga aktiv bertanya bagaimana solusi atau tindakan guru yang tepat agar anak cepat pandai membaca, menulis dan berhitung. Seorang guru ada yang berbagi cerita tentang pengalaman bagaimana suka dukanya mengajarkan membaca, menulis dan berhitung pada anak.

Baik orang tua maupun guru-guru di TK Aku Anak Indonesia sangat senang ketika praktik simulasi bermain dengan media kreatif dari bahan bekas. Permainan yang memang dirancang bertujuan agar anak terstimulasi kemampuan calistungnya.

Setelah selesai bermain dengan media kreatif, masih ada orang tua yang bertanya, tentang cara bagaimana memilih permainan yang tepat bagi anak dan cara membuat permainan dadu huruf dan angka. Sebelumnya, pelaksana berusaha melempar pertanyaan ke forum. Ada seorang guru, bernama ibu WSR yang merespon dengan menjawab bahwa memilih permainan anak tidak harus mahal, murah dan awet. Dadu terbuat dari kardus bekas yang berbentuk dadu, dan dilapisi plastik bening, dan seterusnya. Semua memberi applaus atau tepuk tangan atas jawaban guru tersebut.

Pelaksana menambah penjelasan bahwa orang tua dan guru harus benar-benar selektif dalam membelikan mainan atau membuat mainan sendiri untuk anak. Mainan yang murah, awet, aman, mempunyai nilai Pendidikan. Kalau tujuannya mengenalkan anak baca dan berhitung, permainan tersebut harus berkaitan dengan proses pembelajaran itu sendiri.

Tahap akhir kegiatan pelaksanaan pengabdian masyarakat adalah sesi dokumentasi, penyampaian kesan dan pesan dari peserta baik dari para orang tua maupun guru TK Aku Anak Indonesia serta perpisahan.

\section{SIMPULAN DAN SARAN}

Berdasarkan tahap pelaksanaan pengabdian masyarakat (abdimas ini), maka dapat ditarik simpulan sebagai berikut: 
Program parenting ini sangat diperlukan dalam Lembaga Pendidikan, khususnya lembaga Pendidikan Anak Usia Dini (PAUD) atau TK yang Holistik Integratif (HI) yang hendaknya dilaksanakan secara rutin. Program ini merupakan jembatan komunikasi yang efektif antara pihak orang tua dan guru dalam mendidik anak yang sesuai antara rumah dan di sekolah, supaya perkembangan anak dapat berkembang seoptimal mungkin, khususnya kemampuan anak dalam membaca, menulis dan berhitung (calistung).

Bagi para orang tua murid, program parenting ini sangat bermanfaat, pertama, untuk mendapatkan pengetahuan. tentang bagaimana cara mendidik dan mengajarkan anak di rumah dengan benar, khususnya dalam mestimulasi calistung ini. Kedua, sebagai wadah para orang tua untuk mengungkapkan keluhan, kekawatiran, dan kritik serta saran dicarikan solusinya bersama. Ketiga, meluruskan mind set atau paradigma yang salah tentang cara mendidik anak, khususnya tentang pengajaran membaca, menulis dan berhitung (calistung)

Melalui program parenting ini, guru dapat mendapatkan tambahan wawasan tentang bagaimana metode yang tepat dalam mendidik dan mengajarkan anak di kelas, terutama implementasi pembelajaran dengan stimulasi membaca, menulis dan berhitung (calistung).

Banyaknya kendala pihak Lembaga ketika akan mengadakan program parenting, khususnya yayasan Aku Anak Indonesia, dapat diatasi dengan berkoordinasi dan bermusyawarah antara pihak yang terkait, yaitu dari pihak sekolah, orangtua, nara sumber yang kompeten di bidangnya, bahkan dengan masyarakat sekitar, sehingga bersinergi menciptakan Lembaga pendidikan anak usia dini (PAUD), yang Holistik Integratif (HI) dan menciptakan lingkungan pendidikan yang mengoptimalkan seluruh aspek perkembangan anak didik.

\section{DAFTAR PUSTAKA}

Carey Lou Dick Walter and Carey, J. (2009). The Systematic Design of Instruction. Upper Saddler River, New Jersey: : Pearson Education, Inc.

Dick Walter, C. L. (n.d.). Upper Saddler River, New Jersey: Pearson Education, Inc.

Helmawati. (2015). Menganal dan Memahami Pendidikan Anak Usia Dini. Bandung: Rosdakarya.

Kebudayaan, K. P. (2015). Peraturan Menteri Pendidikan dan Kebudayaan Republik Indonesia Nomor 146 Tahun 2014 tentang Kurikulum 2013 Pendidikan Anak Usia Dini . Jakarta: Kementerian Pendidikan dan Kebudayaan .

Mansur. (2015). Pendidikan Anak usia Dini dalam Islam. Yogyakarta: Pustaka Belajar.

NSPK, Norma, Standar, rosedur, dan Kriteria, Petunjuk Tehnie Penyelenggaraan PAUD Holistik Integratif di Satuan PAUD. (2015). Jakarta: Direktorat Pendidikan Anak Usia Dini, Direktorat Jenderal Pendidikan Anak Usia Dini dan Pendidikan Masyarakat, Kementerian Pendidikan dan Kebudayaan.

Republika. (2017, Desember 23). Info Pendidikan. Retrieved from http://duniakampus7.blogspot.co.id/2015/ 11/dampak-negatif-calistung-bagi.html

Santoso, S. (2004). Pendidikan Anak Usia Dini. Jakarta: Citra Pendidikan Indonesia.

Sudjana, D. (2010). Pendidikan Luar Sekolah: Wawasan Sejarah Perkembangan Filsafah dan Teori Pendukung Asas. Bandung: Falah Production.

Yamin, M. (2009). Kiat Pembelajaran Siswa. Jakarta: Putra Grafika. 